\title{
The Relation of Diabetes Type 2 with Sexual Function among Reproductive Age Women in Iran, a Case-Control Study
}

\author{
Poorandokht Afshari, ${ }^{1}$ Shiva Yazdizadeh, ${ }^{1}$ Parvin Abedi, ${ }^{1}$ and Homayra Rashidi ${ }^{2}$ \\ ${ }^{1}$ Midwifery Department, Reproductive Health Promotion Research Center, Ahvaz Jundishapur University of Medical Sciences, \\ Ahvaz, Iran \\ ${ }^{2}$ Endocrinology Department, Diabetes Research Center, Ahvaz Jundishapur University of Medical Sciences, Ahvaz, Iran
}

Correspondence should be addressed to Parvin Abedi; parvinabedi@ymail.com

Received 19 September 2016; Revised 16 March 2017; Accepted 26 March 2017; Published 6 April 2017

Academic Editor: Alexander Marcus Seifalian

\begin{abstract}
Copyright (C) 2017 Poorandokht Afshari et al. This is an open access article distributed under the Creative Commons Attribution License, which permits unrestricted use, distribution, and reproduction in any medium, provided the original work is properly cited.

Background. Diabetic patients are at the greater risk of retinopathy, nephropathy, neuropathy, and sexual dysfunction compared to the general population. Objective. The aim of this study was to evaluate the sexual dysfunction in type 2 diabetes reproductive age women in Iran. Method. This was a case-control study carried out on 130 women with type 2 diabetes and 130 healthy women. The type 2 diabetes diagnosis was confirmed with abnormal fasting blood sugar, abnormal random blood sugar test, and abnormal level of $\mathrm{HbAlC}$. Eligible women were requested to complete a demographic questionnaire and female sexual function index (FSFI). The chi-square test, independent $t$-test, and Multivariate Analysis of Covariance (MANCOVA) were used for analyzing data. Results. Results of this study showed that diabetic women had significantly lower sexual desire, arousal, lubrication, and orgasm and more pain compared to the healthy women $(p<0.05)$. Also diabetic women had lower sexual satisfaction compared to the healthy women $(p=0.002)$. The total score of sexual function was significantly lower in the diabetic women compared to the healthy women (21.25 \pm 7.04 versus $22.43 \pm 7.6, p=0.004)$. Conclusion. Results of this study showed that the score of all dimensions of sexual function in diabetic patients was lower than that in healthy women. Education and counseling about controlling diabetes and sexual function among diabetic women in reproductive age are recommended.
\end{abstract}

\section{Introduction}

Type 2 diabetes is a chronic disease with an adult-onset and mostly is independent of insulin [1]. Type 2 diabetes may happen in condition that the body resisted the effects of insulin or there is not enough secretion of insulin [2]. Globally, 285 million people are affected with type 2 diabetes, which is anticipated to reach 438 million by the year of 2030 [3]. The prevalence of diabetes in Asian countries due to the rapid development and urbanization is expected to be nearly $60 \%$ of the world's diabetic population [4]. The prevalence of type 2 diabetes in Iranian population $>40$ years has been reported as $24 \%$ where the risk in women is greater than men $(p<0.001)$ [5]. In a study on 14,993 people in Yazd province, Iran, results showed that the prevalence of type 2 diabetes was $16.3 \%$ and age and sex were important related factors [6].
Type 2 diabetes may have complications such as microvascular damage, with the highest incidence for retinopathy [7], nephropathy [8], and neuropathy [9]. Due to the damage to nerves and blood vessels in uncontrolled diabetes, sexual dysfunction in men and women may happen [10]. A study was conducted by Enzlin et al. on 120 women with type 1 diabetes and 180 healthy women to evaluate the relation of sexual dysfunction with type 1 diabetes. Results showed that women with diabetes were more likely to have sexual dysfunction ( $27 \%$ versus $15 \%, p=0.04$ ) and only lubrication showed significant difference between two groups [11].

A cross-sectional study was conducted on 110 women with diabetes who were randomly divided into two groups with or without sexual dysfunction. Results showed that $53.6 \%$ of women had sexual dysfunction and there was a significant relation between albuminuria and sexual dysfunction 
$(p=0.001)$ and also retinopathy and sexual dysfunction $(p=0.007)[12]$.

A descriptive study among 150 women aged $20-60$ years with type 2 diabetes in Iran showed that the mean sexual function score was 22 and $78.7 \%$ of women had sexual dysfunction [13]. On the other hand, some studies showed that there is no relation between diabetes type 2 and sexual dysfunction. Ismail et al., in a study on 347 women (174 healthy women and 173 diabetic women), found that prevalence of orgasmic disorders was $13.3 \%$ and $10.3 \%$ in diabetic and healthy women, respectively, where the differences were not significant [14].

There is not enough information on relation of type 2 diabetes and sexual function and satisfaction in Iran. Therefore, this study was designed to evaluate the relation of type 2 diabetes and sexual function among reproductive age women in Iran.

\section{Material and Methods}

This was a case-control study in which 130 women with type 2 diabetes and 130 healthy women were recruited. The study design was approved by the Ethics Committee of Ahvaz Jundishapur University of Medical Sciences. This study was started in January and completed in June 2014. The inclusion criteria were as follows: married women, healthy women (control group), and women who had type 2 diabetes (case group), body mass index $19.8-29 \mathrm{~kg} / \mathrm{m}^{2}$, age $15-45$, and ability to read and write. Women who were menopausal and had severe mental problems were excluded from the study. The type 2 diabetes diagnosis was confirmed with abnormal fasting blood sugar, abnormal random blood sugar test, and abnormal level of HbAlC. The presence of nephropathy was confirmed by increased urinary albumin excretion in the absence of other kidney diseases [15]. The criteria announced by American Academy of Neurology were considered for detection of neuropathy [16]. The diagnosis of retinopathy was confirmed by criteria recommended by the American Academy of Ophthalmology [17]. All diabetic patients were recruited from diabetic clinic and Research Center affiliated to Ahvaz Jundishapur University of Medical Sciences, Ahvaz, Iran, and had comprehensive medical record, while healthy women were recruited from two public health centers. A written informed consent was obtained before data collection.

Eligible women were requested to complete a demographic questionnaire and female sexual function index (FSFI), while one of the researchers (SY) attended if women had any ambiguity in questions. The FSFI questionnaire has 19 questions for measuring six domains of sexual activity including desire, arousal, lubrication, orgasm, pain, and sexual satisfaction. In this questionnaire, two questions were considered for measuring sexual desire, four for each area of lubrication and arousal, and three questions for each area of orgasm, sexual satisfaction, and pain. A five-point Likert scale was used for scoring. The total score of each domain was multiplied in the certain factor. The factor for desire was 0.6, 0.3 for arousal and lubrication, and 0.4 for other domains. The sexual dysfunction is defined as total number of FSFI < 26 [18]. Fakhri et al. assessed the validity and reliability of this questionnaire in Iran, and results showed that this questionnaire is suitable for measuring sexual function in Iranian women [19]. All participants responded to the Persian version of FSFI questionnaire that was validated in Iran.

\section{Statistics}

All data was entered using SPSS version 16. The chi-square test was used for comparing the nonparametric data, while independent $t$-test was used for comparing parametric figures. The Multivariate Analysis of Covariance (MANCOVA) was used for comparing sexual function between diabetic and healthy women when the components of sexual function were considered as dependent variable and group considered as independent variable. Age, job, education level, economic situation, place of living, and spouse's job have been entered to the MANCOVA model as a covariate. The results were considered significant if $p<0.05$.

\section{Results}

At the end of study, 106 questionnaires related to the case group and 128 questionnaires related to the control group were completed. Results of this study showed that diabetic patients were significantly older than healthy women (43.3 \pm 10.7 versus $37.9 \pm 7.7, p<0.001$ ). The number of children did not show any significant difference between two groups $(1.91 \pm 2.5$ versus $2.24 \pm 2.4$, in the case and control groups, resp., $p=0.32$ ). The level of education was significantly higher in the control group compared to the diabetic women (32\% of women in the control group had university education compared to $14.2 \%$ in the case group, $p=0.001$ ). Other demographic characteristics of two groups are listed in Table 1.

Some information about diabetes is presented in Table 2 . According to this table, the mean duration of disease was $6.7 \pm 5.5$ years, $3.8 \%$ patients had history of cardiac diseases, and $6.6 \%$ of them reported history of renal disease. Fortyone (38.7\%) diabetic women were under the insulin therapy, because their disease was not controlled by oral medication. However according to the results of fasting blood sugar (mean: $154.8 \pm 74.4$ ) and $\mathrm{HbAlC}$ (mean: $9.55 \pm 3.4$ ) the disease was not controlled among them. Almost half of the women were suffering from retinopathy $(42.2 \%)$.

Table 3 indicates information about sexual function between two groups. Results of this study showed that diabetic patients had significantly lower sexual desire, arousal, lubrication, and orgasm and more pain compared to the healthy women $(p<0.05)$. Also diabetic women had lower sexual satisfaction compared to the healthy women $(p=$ 0.002). The total score of sexual function was significantly lower in the diabetic women compared to the healthy women $(21.25 \pm 7.04$ versus $22.43 \pm 7.6, p=0.004)$ (Table 3$)$.

\section{Discussion}

This study was designed to explore the relation of type 2 diabetes and sexual function in a case-control study. Results of this study showed that, despite treatment, the diabetes was 
TABLE 1: The sociodemographic characteristics of participants in two groups of diabetic and healthy women.

\begin{tabular}{|c|c|c|c|}
\hline \multirow[t]{2}{*}{ Variables } & $\begin{array}{c}\text { Diabetic } \\
n=106\end{array}$ & $\begin{array}{l}\text { Normal } \\
n=128\end{array}$ & \multirow[t]{2}{*}{$p$ value } \\
\hline & \multicolumn{2}{|c|}{ Mean \pm SD or $n(\%)$} & \\
\hline Age (y) & $43.3 \pm 10.7$ & $37.9 \pm 7.7$ & $<0.001$ \\
\hline Spouse's age (y) & $48.6 \pm 12.3$ & $45.5 \pm 10.2$ & 0.083 \\
\hline $\begin{array}{l}\text { Number of } \\
\text { children }\end{array}$ & $1.91 \pm 2.5$ & $2.24 \pm 2.4$ & 0.32 \\
\hline \multicolumn{4}{|l|}{$J o b$} \\
\hline Employee & $14(13.2)$ & $38(29.7)$ & \multirow{2}{*}{0.003} \\
\hline Housewife & $92(86.8)$ & $90(70.3)$ & \\
\hline \multicolumn{4}{|l|}{ Education } \\
\hline Primary & $25(23.6)$ & $11(8.6)$ & \multirow{4}{*}{0.001} \\
\hline High school & $28(26.5)$ & $22(17.2)$ & \\
\hline Diploma & $38(35.8)$ & $54(42.2)$ & \\
\hline University & $15(14.2)$ & $41(32)$ & \\
\hline $\begin{array}{l}\text { Women who were } \\
\text { the only wife of } \\
\text { their husband }\end{array}$ & $99(93.4)$ & $120(93.6)$ & \multirow[b]{2}{*}{0.91} \\
\hline $\begin{array}{l}\text { Women whose } \\
\text { husbands had } \\
\text { another wife }\end{array}$ & $7(6.6)$ & $8(6.3)$ & \\
\hline \multicolumn{4}{|l|}{ Place of living } \\
\hline Rural & $9(8.5)$ & $6(4.7)$ & \multirow{2}{*}{0.23} \\
\hline City & 97 (91.5) & $122(95.3)$ & \\
\hline \multicolumn{4}{|l|}{ Economic situation } \\
\hline Good & 40 (37.7) & $61(48)$ & \multirow{3}{*}{0.18} \\
\hline Moderate & 49 (46.2) & $56(44.1)$ & \\
\hline Weak & $17(16)$ & $10(7.9)$ & \\
\hline
\end{tabular}

For the continuous variables the independent $t$-test was used, while, for the categorical data, the chi-square test was used.

poorly controlled in the diabetic patients and most women in this group had retinopathy.

Based on the normal distribution assumption in the statistical analyses, results of this study indicated that all areas of sexual function significantly were impaired in diabetic women. Results of other studies also indicated impaired sexual function in diabetic women. A study was conducted by Erol et al. on 72 reproductive age diabetic women and 60 age matched healthy women. Results showed that the most common symptom in diabetic patients was lack of libido (77\%) following by vaginal dryness (41.6\%) and orgasmic dysfunction $(49 \%)$ and there was a significant difference in all areas of sexual function between two groups [20]. These results are in line with our results as in our study; all dimensions of sexual function in the diabetic women group were impaired compared to the healthy women.

A study by J. Olarinoye and A. Olarinoye, on 51 women with type 2 diabetes who were compared with 39 healthy women, showed that the total score of sexual function was significantly lower in diabetic patients compared to healthy women $(20.5 \pm 8.3$ compared to $31.2 \pm 8.8, p<0.001)$. Also the
TABLE 2: The history of chronic disease, medication, and medical complications among diabetic patients.

\begin{tabular}{lc}
\hline Variables & $\begin{array}{c}\text { Diabetic } n=106 \\
\text { Mean } \pm \text { SD or } N(\%)\end{array}$ \\
\hline Duration of disease (y) & $6.7 \pm 5.5$ \\
History of cardiac diseases & $4(3.8)$ \\
Renal disease & $7(6.6)$ \\
Medication & \\
Insulin & $41(38.7)$ \\
Metformin + glibenclamide & $65(61.3)$ \\
Laboratories tests & \\
Fasting blood sugar & $154.8 \pm 74.4$ \\
2-hour blood sugar & $215.6 \pm 87$ \\
HbA1C & $9.55 \pm 3.4$ \\
Diabetic complications & \\
Nephropathy & $9(8.5)$ \\
Retinopathy & $45(42.5)$ \\
Heart problem & $9(8.49)$ \\
Liver problem & $6(5.6)$ \\
Extremities neuropathy & $15(14.1)$ \\
\hline
\end{tabular}

TABLE 3: The scores of different dimensions of sexual function in diabetic and healthy women.

\begin{tabular}{lccc}
\hline Variables & $\begin{array}{c}\text { Diabetic } \\
n=106\end{array}$ & $\begin{array}{c}\text { Normal } \\
n=128\end{array}$ & $p$ value \\
& \multicolumn{2}{c}{ Mean \pm SD } & \\
\hline Sexual desire & $3.34 \pm 1.37$ & $3.69 \pm 1.19$ & $<0.001$ \\
Arousal & $3.66 \pm 1.37$ & $3.79 \pm 1.39$ & $<0.001$ \\
Lubrication & $3.62 \pm 1.25$ & $4.05 \pm 1.39$ & 0.02 \\
$\begin{array}{l}\text { Orgasm } \\
\text { Sexual }\end{array}$ & $3.68 \pm 1.42$ & $3.86 \pm 1.47$ & 0.007 \\
satisfaction & $4.01 \pm 1.33$ & $4.08 \pm 1.36$ & 0.002 \\
$\begin{array}{l}\text { Dyspareunia } \\
\text { Total score of }\end{array}$ & $4.03 \pm 1.45$ & $3.99 \pm 1.54$ & 0.06 \\
sexual function & $21.25 \pm 7.04$ & $22.43 \pm 7.6$ & 0.004 \\
\hline
\end{tabular}

For all variables, age, job, education level, economic situation, place of living, and spouse's job have been entered to the MANCOVA model as a covariate.

scores of all dimensions of sexual function were significantly lower in diabetic patients compared to the healthy women $(p<0.05)$ which shows the interrelationship between various domains of women's sexual functioning [21]. The total score of sexual function in our study was $21.25 \pm 7.04$ and $22.43 \pm 7.6$ in the diabetic and healthy women, respectively, which is lower in the healthy women than that in the study of J. Olarinoye and A. Olarinoye. Other studies in Iran also showed that the prevalence of sexual dysfunction among reproductive age women is $27.3 \%$ [22]. High blood sugar in diabetic women may lead to reduced tissue and nerve supply especially in sexual organs. This matter affects lubrication and causes reduced sensation in the vagina and therefore painful intercourse and reduced orgasm [23]. 
A study on 420 women with type 2 diabetes with mean age of $54.4 \pm 9.8$ years in Tehran, Iran, showed that the average score of FSFI was 14.61 and totally $94.4 \%$ of women had sexual dysfunction. Sexual dysfunction was observed in 247 (90.5\%) of nonmenopausal women and 153 (98.7\%) of postmenopausal women [24]. These results are not in line with our results. The reason for this discrepancy may be due to the fact that the women in the Shadman et al's study were older than those in our study. Although authors mentioned that $90.5 \%$ of women were not menopausal, according to the mean age of participants they were in perimenopausal age. According to other studies, the sexual function deteriorates in perimenopausal women [25].

A study was conducted by Vafaeimanesh et al., on 110 women with type 2 diabetes in Iran who were divided into two groups of sexual dysfunction and normal sexual function. Results showed that 59 (53.6\%) of women had sexual dysfunction. There was no significant difference in the age of women with sexual dysfunction and normal sexual function (48.22 \pm 6.6 versus $48.14 \pm 5.37$ years). There was a significant association between sexual dysfunction and retinopathy $(p=0.007)$, but not with neuropathy [12].

In the present study $41(38.7 \%)$ of patients used insulin for their disease. However the mean of $\mathrm{HbAlC}$ was $9.55 \pm 3.4$ which is much higher than the cut-off (6.5\%) which was recommended by American Diabetes Association for diabetes [9]. In the Vafaeimanesh et al's study also the mean of HbAIC was $8.20 \pm 1.33$ which was higher than the cut-off, but lower than what we found in this study. It seems women with type 2 diabetes in Ahvaz need more education about their lifestyle and medications.

\section{Strength and Limitation of the Study}

All women with diabetes type 2 were selected from Diabetes Research Center affiliated to Ahvaz Jundishapur University of Medical Sciences, Ahvaz, Iran, which is a referral center for all diabetic patients in Ahvaz. We did not evaluate the husbands of women regarding chronic diseases. Other studies stated that women with diabetic husband had more sexual dysfunction [26].

\section{Conclusion}

Results of this study showed that the score of all dimensions of sexual function in diabetic patients is lower than that in healthy women. Education and counseling about controlling diabetes and sexual function among diabetic women in reproductive age are recommended.

\section{Conflicts of Interest}

The authors declare that there are no conflicts of interest regarding the publication of this paper.

\section{Acknowledgments}

This study is a part of research work done in the Ahvaz Jundishapur University of Medical Sciences. All expenses are provided by Ahvaz Jundishapur University of Medical Sciences, Ahvaz, Iran. The authors would like to thank all women who participated in this study. Thanks are also extended to the Diabetes Research Center.

\section{References}

[1] Diabetes Mellitus (DM), “The Merck Manuals: The Merck Manual for Health Care Professionals," http://www.merckmanuals .com/professional/endocrine_and_metabolic_disorders/diabetes_mellitus_and_disorders_of_carbohydrate_metabolism/diabetes_mellitus_dm.html.

[2] M. A. Papadakis, S. J. Mcphee, and M. W. Rabow, Current Medical Diagnosis \& Treatment, The McGraw-Hill Companies, New York, NY, USA, 53rd edition, 2014.

[3] P. Zhang, X. Zhang, J. Brown et al., "Global healthcare expenditure on diabetes for 2010 and 2030," Diabetes Research and Clinical Practice, vol. 87, no. 3, pp. 293-301, 2010.

[4] J. C. N. Chan, V. Malik, W. Jia et al., "Diabetes in Asia: epidemiology, risk factors, and pathophysiology," JAMA, vol. 301, no. 20, pp. 2129-2140, 2009.

[5] A. A. Haghdoost, M. Rezazadeh-Kermani, B. Sadghirad, and H. R. Baradaran, "Prevalence of type 2 diabetes in the Islamic Republic of Iran: systematic review and meta-analysis," Eastern Mediterranean Health Journal, vol. 15, no. 3, pp. 591-599, 2009.

[6] M. H. A. Lotfi, H. Saadati, and M. Afzali, "Prevalence of diabetes in people aged $\geq 30$ years: the results of screen-ing program of Yazd Province, Iran, in 2012," Journal of research in health sciences, vol. 14, no. 1, pp. 87-91, 2014.

[7] D. S. Fong, L. P. Aiello, F. L. Ferris III, and R. Klein, "Diabetic retinopathy," Diabetes Care, vol. 27, no. 10, pp. 2540-2553, 2004.

[8] J. L. Gross, M. J. De Azevedo, S. P. Silveiro, L. H. Canani, M. L. Caramori, and T. Zelmanovitz, "Diabetic nephropathy: diagnosis, prevention, and treatment," Diabetes Care, vol. 28, no. 1, pp. 164-176, 2005.

[9] American Diabetes Association, "Standards of medical care in diabetes-2011," Diabetes Care, vol. 34, supplement 1, pp. S11S61, 2011.

[10] M. Vroomen-Durning, "Type 2 diabetes and your sexuality," http://www.everydayhealth.com/diabetes/type2/understanding/ diabetes-and-sexual-health.aspx.

[11] P. Enzlin, C. Mathieu, A. Van den Bruel, J. Bosteels, D. Vanderschueren, and K. Demyttenaere, "Sexual dysfunction in women with type 1 diabetes: a controlled study," Diabetes Care, vol. 25, no. 4, pp. 672-677, 2002.

[12] J. Vafaeimanesh, M. Raei, F. Hosseinzadeh, and M. Parham, "Evaluation of sexual dysfunction in women with type 2 diabetes," Indian Journal of Endocrinology and Metabolism, vol. 18, no. 2, pp. 175-179, 2014.

[13] F. Elyasi, Z. Kashi, B. Tasfieh, A. Bahar, and M. Khademloo, "Sexual dysfunction in women with type 2 diabetes mellitus," Iranian Journal of Medical Sciences, vol. 40, no. 3, pp. 206-213, 2015.

[14] A. H. Ismail, R. Baw, H. Sidi et al., "Orgasmic dysfunction among Malay diabetic women in Malaysia," Comprehensive Psychiatry, vol. 55, supplement 1, pp. S29-S33, 2014.

[15] American Diabetes Association, "Nephropathy in diabetes," Diabetes Care, vol. 27, supplement 1, pp. S79-S83, 2004.

[16] J. D. England, G. S. Gronseth, G. Franklin et al., "American Academy of Neurology, American Association of Electrodiagnostic Medicine, American Academy of Physical Medicine 
and Rehabilitation. Distal symmetric polyneuropathy: a definition for clinical research: report of the American Academy of Neurology, the American Association of Electrodiagnostic Medicine, and the American Academy of Physical Medicine and Rehabilitation," Neurology, vol. 64, no. 2, pp. 199-207, 2005.

[17] American Academy of Ophthalmology, Information Statement Screening for Diabetic Retinopathy, November 2006, Updated 2014.

[18] R. Rosen, C. Brown, J. Heiman et al., "The Female Sexual Function Index (FSFI): a multidimensional self-report instrument for the assessment of female sexual function," Journal of Sex and Marital Therapy, vol. 26, no. 2, pp. 191-208, 2000.

[19] A. Fakhri, A. H. Pakpour, A. Burri, H. Morshedi, and I. M. Zeidi, "The female sexual function index: translation and validation of an Iranian version," The Journal of Sexual Medicine, vol. 9, no. 2, pp. 514-523, 2012.

[20] B. Erol, A. Tefekli, I. Ozbey et al., "Sexual dysfunction in type II diabetic females: a comparative study," Journal of Sex and Marital Therapy, vol. 28, supplement 1, pp. 55-62, 2002.

[21] J. Olarinoye and A. Olarinoye, "Determinants of sexual function among women with type 2 diabetes in a Nigerian population," Journal of Sexual Medicine, vol. 5, no. 4, pp. 878-886, 2008.

[22] F. R. Tehrani, M. Farahmand, M. Simbar, and H. M. Afzali, "Factors associated with sexual dysfunction; a population based study in Iranian reproductive age women," Archives of Iranian Medicine, vol. 17, no. 10, pp. 679-684, 2014.

[23] Diabetes Research Wellness Foundation, "Sexual dysfunction and diabetes in women," https://www.diabeteswellness.net/sites/ default/files/Sexual\%20Dysfunction\%20and\%20Diabetes\%20in $\% 20$ Women.pdf.

[24] Z. Shadman, M. Akhoundan, N. Poorsoltan, B. Larijani, S. M. Arzaghi, and M. Khoshniat, "Factors associated with sexual function in iranian women with type 2 diabetes mellitus: partner relationship as the most important predictor," Iranian Red Crescent Medical Journal, vol. 16, no. 3, Article ID e14941, 2014.

[25] L. Dennerstein, J. Randolph, J. Taffe, E. Dudley, and H. Burger, "Hormones, mood, sexuality, and the menopausal transition," Fertility and Sterility, vol. 77, supplement 4, pp. S42-S48, 2002.

[26] A. K. Koolaee, E. Asadi, L. Mansoor, L. Mosalanejad, and A. F. Abadi, "A holistic approach to psychological sexual problems in women with diabetic husbands," Iranian Journal of Reproductive Medicine, vol. 12, no. 3, pp. 175-182, 2014. 


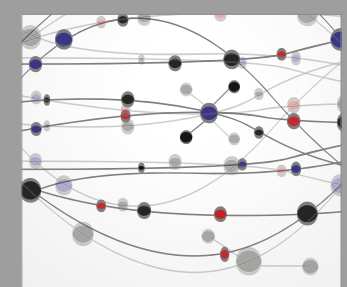

The Scientific World Journal
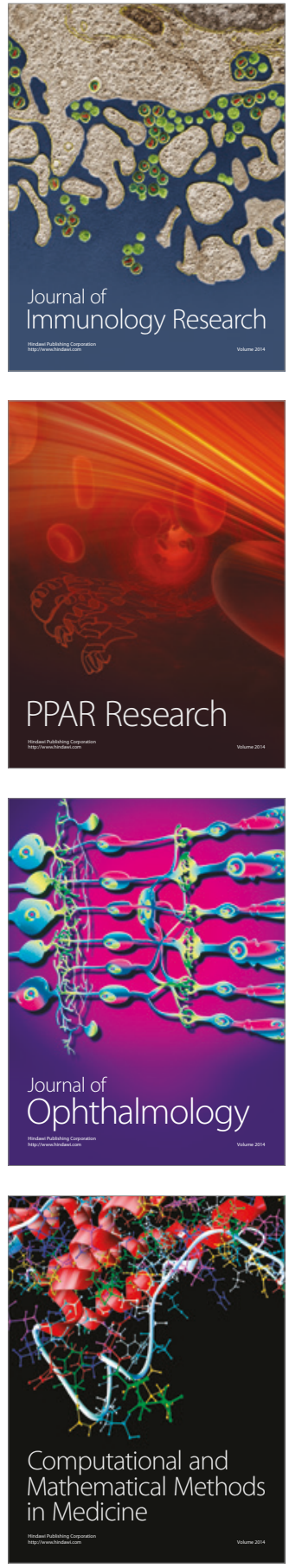

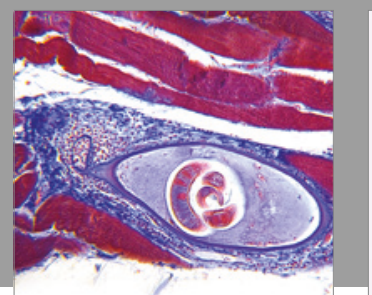

Gastroenterology Research and Practice
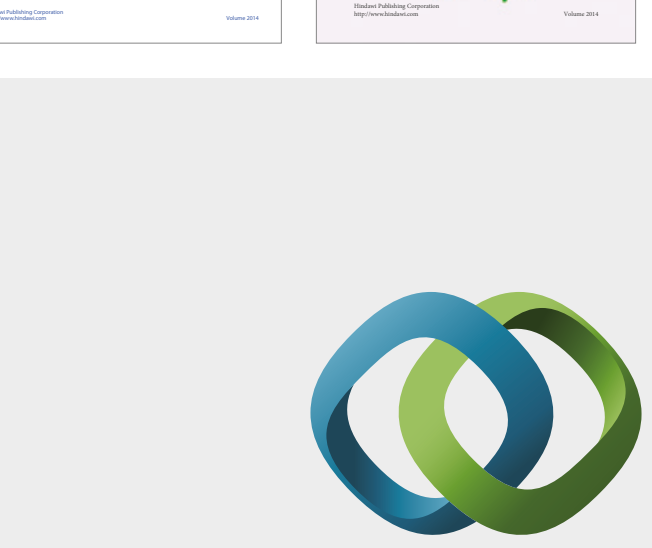

\section{Hindawi}

Submit your manuscripts at

https://www.hindawi.com
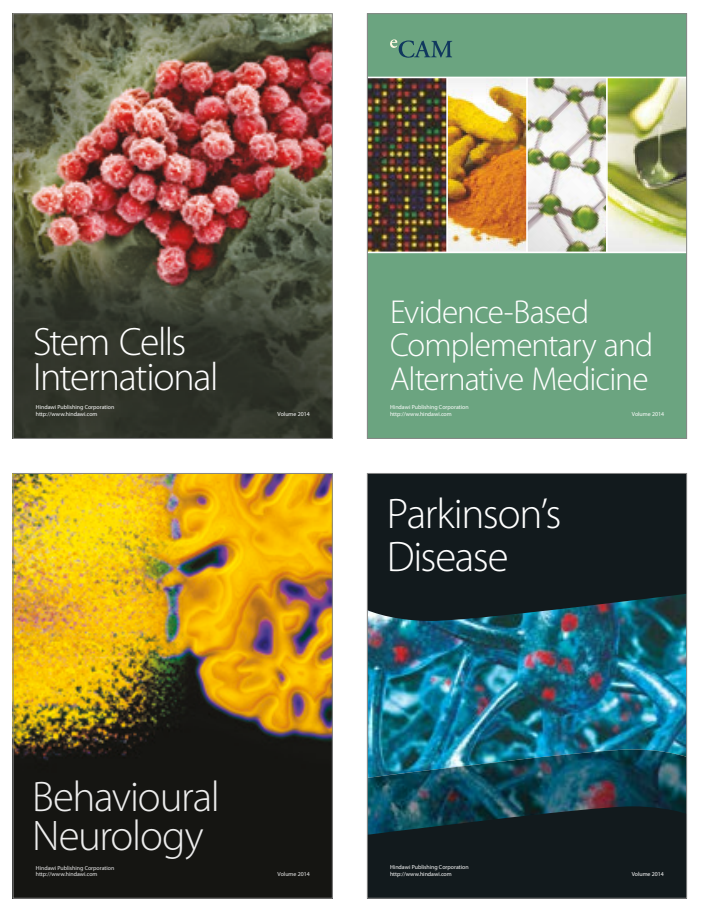
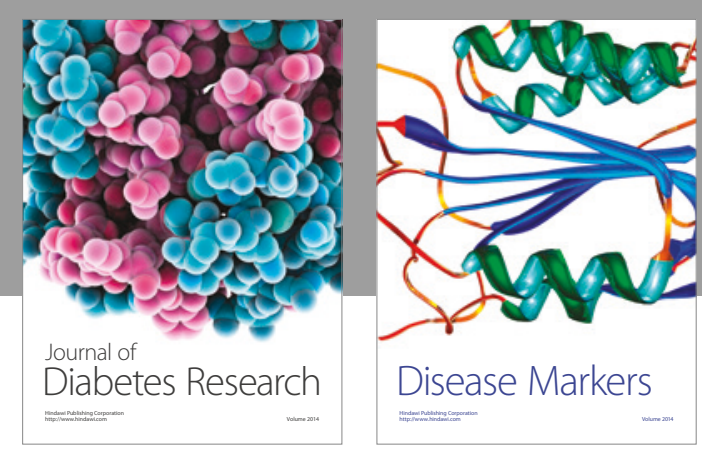

Disease Markers
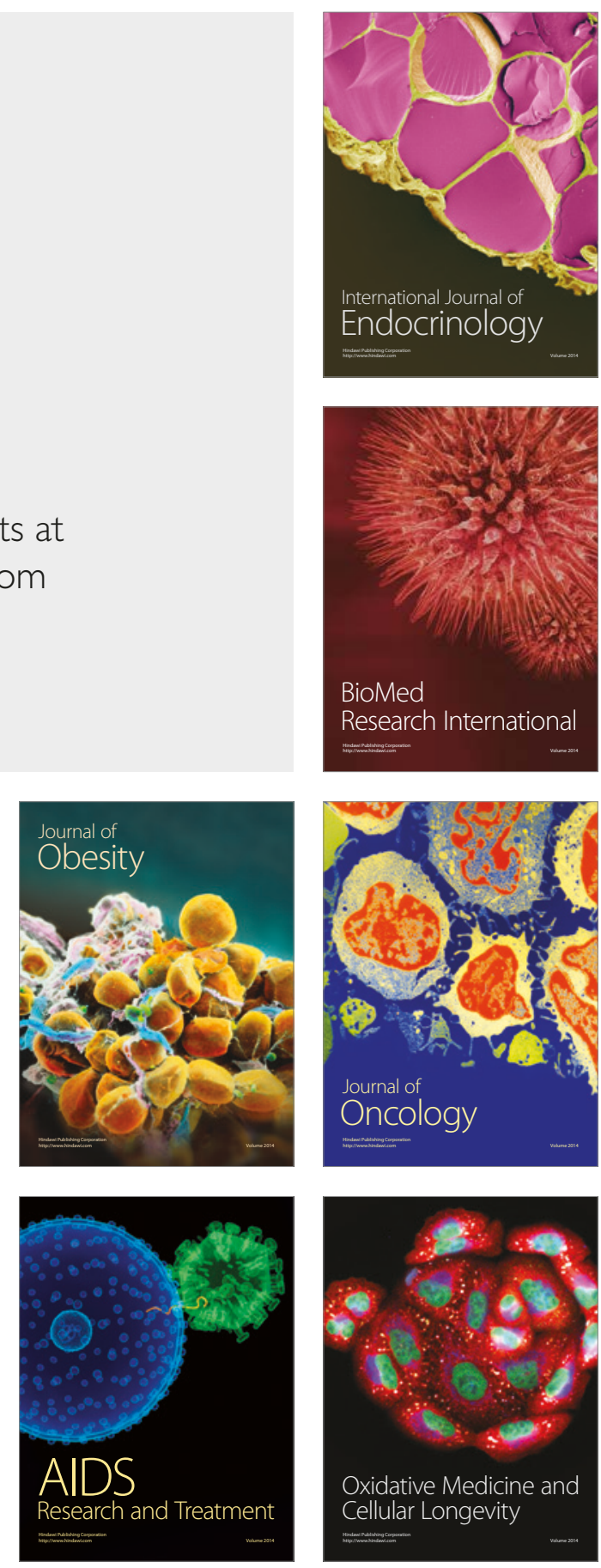